\title{
Program "Cultural Heritage" - innovation of archeology, history and art in the context of the development of education in the Republic of Kazakhstan
}

Yeldos Maksatovich Kariyev a *,

Suggested Citation:

Humanities and Social Sciences.

New Trends and Issues Proceedings on

Abstract

$*$ Yeldos Maksatovich Kariyev ,

E-mail address 
Sciences.

1. Introduction

2. Main Part 
Sciences.

D

D

D

D

D

D 
Sciences. 
Sciences.

3. Conclusion 
Sciences.

\section{References}

Science,

. Political

Banner of Labor, 4,

Asia Center

The country and the world

"Aknualni Vymozenosti Vedy-2014»,

Materialy X mezinarodnoi vedecko-prakticka conference D D

D

Sayasat,

D 
Series, 